\title{
Technical Efficiency of Wheat Producing Farmers in the Case of Bale Zone of Oromia Region, Ethiopia: An Application of Stochastic Frontier Approach
}

\author{
Endalew Muluneh Amena* \\ College of Agriculture and Natural Resources, Madda Walabu University \\ PO box 247, Bale Robe, Oromia region, Ethiopia \\ Gemechu Mulatu \\ College of Business and Economics, Madda Walabu University \\ PO box 247, Bale Robe, Oromia region, Ethiopia
}

\begin{abstract}
The research is financed by Madda Walabu University
Abstract

This study was designed to investigate the level of wheat producing farmer's efficiency and its major determining factors in Bale zone. Both primary and secondary information were collected and multi stage sampling techniques was used to collect the primary information. In the first stage, three woredas were identified purposively for the main reasons that wheat is the most important cereal crops produced in the districts. In the second stage, two administrative kebeles were purposively selected for similar reason of potential wheat production, and in sum 6 administrative kebeles were selected and the total sample size (n) of 344 households was determined. Stochastic production frontier approach was used in this study which Cobb-Douglas production functional was selected for the study. Given the functional form used, estimation procedure implemented, distributional assumption of the inefficient effect, ui, the mean technical efficiency is estimated to be $67 \%$. This value indicates that most farmers are not technically efficient in producing wheat in the study area in that on average they can increase the output they are currently obtaining by 33 percent without increasing the existing level of inputs; labor, area and seed. Education attainment of the household, sex of household head, asset owned, extension contact, membership in iddir, distance to nearby all wheather road, family size, and adption of new variety seed were identified to be the variables significanlty affecting the efficiency of wheat producing farmers. Government should work further to improve educational status of farmers, strengthen the effectiveness of extension services in order to enhance the level of household's technical efficiency and there should also be effective way to disseminate new variety seeds and new technologies in order to enhance technical efficiency of wheat production.
\end{abstract}

Keywords: efficiency, technical efficiency, wheat production, food security

DOI: $10.7176 / \mathrm{JESD} / 11-11-07$

Publication date:June 30th 2020

\section{INTRODUCTION}

Even though the share of service sector is increasing, agricultural sector remained the single largest sector dominating the economy of Ethiopia. The sector accounts for more than $45 \%$ of GDP and employing over $77 \%$ of the labor force followed by service sector which employs $18 \%$ of the total labor force of the country. The sector contributes about $80 \%$ of foreign exchange earnings and more than $70 \%$ of raw material for industrial sectors in the country (Word Bank, 2016). This implies that increase/decrease in agricultural productivity has significant impact on the overall economic the country. On the other hand, the agricultural production in the country is susceptible to climate change and other dynamic conditions such as increased incidence and severity of drought which greatly affect its productivity. Literature revealed that $60 \%$ of the sector's share goes to crop production whereas livestock production accounts for about $27 \%$ and other activities account for $13 \%$ of the output (Mann and Warner, 2015).

According to Central Statistics Agency agricultural sample survey report of 2017/18 a total lands of 12677882.27 hectare were covered by grain crops, i.e cereals, pulses and oil seeds, from which a total volume of about 306126383.06 quintals of grain crops were obtained CSA (2018). From these grain crops, cereal crops are the dominant produced crops in the country. About 10232582.23 hectares $(80.71 \%$ of total land covered by grain crops) of land covered by cereals crops and 267789764.02 .61 (87.48\% out of total grain crop production) quintals of cereal crops were produced in 2017/18. According to this report, grain crops: cereals, pulses and oilseed are produced as food crops for majority of the country's population and serve as a source of income at household level as well as contribute for the country's foreign earning currency. Smallholder farmers by rain fed agricultural system mainly cultivate these cereal crops.

From major cultivated cereal crops, wheat production is the most dominant agricultural activities practiced in the country. Out of total land covered by grain crops, 1,696,907.05 hectare of land (13.38\%) was covered by 
wheat during 2017/18. Wheat is mainly produced in Oromia, Amhara and Southern Nation Nationality and People Regional State. According to (CSA, 2018) the wheat varieties of bread (Triticum aestivum) and durum (T. turgidum var. durum) where distributed with about 4.84 million smallholder farmers. With this potential, Ethiopia is identified to be the second largest country in African countries in producing wheat mostly at the highland areas ranging between 6 and $16^{\circ} \mathrm{N}, 35$ and $42^{\circ} \mathrm{E}$, and from 1500 to $2800 \mathrm{~m}$ ( Solomon,2014 and Workineh,2016).

Relative to other regions, Wheat is largely produced in highlands of Oromia region. According to Kaleb and Workneh (2016), the largest volume of the main season production of wheat originates from Oromia which constitute around 55\% of the country's total wheat production followed by Amhara and SNNP with 29 and 9\% respectively. Arsi, Bale and Shewa zones of Oromia region are the most known areas where wheat is widely produced alongside with other major crops such as barley, maize, sorghum, finger millets, pulses, oilseed, fruits and vegetables. Despite its potential for wheat grain production, Ethiopia falls short of being self-sufficient in wheat production, and is currently a net importer of wheat grain in which much of the domestic wheat demand of flourmill factories is met through imports. Similar to other wheat producing zone, Wheat production at in Bale zone of Oromia region lacks productivity and efficiency despite significant efforts made by government, nongovernment organization, research centers and higher educational institutions.

Surprisingly, despite the potential, wheat is the single most important staple imported from abroad (Kaleb and Workneh, 2016). Significant proportions of rural households even at potential wheat production areas of the country are in need of food aid. Improving efficiency of wheat production through introducing different production mechanisms needs appropriate information and understanding of the level of efficiency of wheat producing farmers/in our case technical efficiency/ and the major factors that affect the level of efficiency in production of wheat at the study area. However, the questions such as what is the extent of inefficiency/technical inefficiency in our case/ of wheat producing farmers and related basic information are remained unanswered at the study area. This calls for the need for measuring the technical efficiency of wheat producing farmers using stochastic frontier production function (SFF)

Therefore, this study is designed to fill the gap. It investigated farm level of wheat producing farmer's efficiency and put the way forwards to improve wheat producing farmer's technical efficiency at the study area and their success and failures. Specifically, the research was designed to address the following objectives: to measure the level of technical efficiency of wheat producing farmers in the study area; to identify factors determining technical efficiency of wheat producing farmers in the study area; to identify indigenous means of improving technical efficiency at the study area

\section{Methodologies}

\subsection{Sources of data, Method of data collection and sampling techniques}

The researchers employed both primary and secondary data sources to gather the necessary information needed to achieve the stated objectives. The primary data was collected using semi-structured questionnaire were administered by the well-trained data collectors/enumerators. In addition to this FGD (focal group discussion) and key informant interview were used to collect relevant and detail information. Secondary data was collected from Agricultural and rural development offices both at zonal level and woreda/district level, different NGOs in the district.

Multi stage sampling techniques was used to collect the primary information. In the first stage, three Woredas were identified purposively for the main reasons that wheat is the most important cereal crops produced in the district. In the second stage, two administrative kebeles were purposively selected for similar reason of potential wheat production, and in sum, 6 administrative kebeles were selected. Finally, proportional random sampling technique was used to take sample from each administrative Kebeles;namely: Ginhir(Harda Qabisa,Karraa kebeles), Agarfa(Alii and Elbidu kebeles) and sinana(Salqaa and Walta'ii Arjoo kebeles ) woredas from which the total sample size (n) of 344 households was determined

\subsection{Method of data Analysis}

\section{The Stochastic Frontier Approach (SFA)}

To analyze the data to be collected from primary and secondary sources, both descriptive statistics and Econometric models were employed.

Quantitatively, as since agricultural production is most of the time affected by random shocks, stochastic frontier approach was used in this study. Following (Aigner, et.al., 1977) the stochastic frontier is presented as follows:

$\mathrm{Yi}=\exp (X i \beta+\mathrm{Vi}-\mathrm{Ui})$

Where

$\mathrm{Yi}$-denotes the output for the $\mathrm{i}^{\text {th }}$ sample farm

$\mathrm{Xi}$ - represents a $(1 \mathrm{x})$ vector whose values are functions of inputs and explanatory variables for the $\mathrm{i}^{\text {th }}$ farm $\beta$ $=$ is a $(\mathrm{K} \times 1)$ vector of unknown parameters to be estimated

Vis- are assumed to be independent and identically distributed random errors which have normal distribution with 
mean zero and unknown variables, and

$\mathrm{U}_{\text {is- }}$ are non-negative unobservable associated with the technical inefficiency of production such that for a given technology and levels of inputs, the observed output falls short of its potential output ( or it is a one-sided error term $(U \geq 0)$ efficiency component that represents the technical inefficiency of the farm

Efficient transformation of inputs into output is characterized by the production function $f(\mathrm{Xi})$, which shows the maximum output obtainable from various input vectors. The stochastic frontier production function assumes the presence of technical inefficiency of production. Hence, the function is defined as:

$Y i=f(X i, \beta)+\epsilon i$

Where

$\varepsilon$ is the error term that is composed of two elements, that is

$\varepsilon \mathrm{i}=\mathrm{Vi}-\mathrm{Ui}$

The stochastic frontier analysis has been used in many studies like by Yami et al. (2013; Beshir et al. (2012); Jaime and Salazar (2011); Tan et al. (2010); Daniel et al. (2008) and Amaza et al. (2006) and the approach specifies technical efficiency as the ratio of the observed output to the frontier output, that means the technical efficiency of an individual farmer or farm is defined as the ratio of observed output and the corresponding frontier output, given the state of available technology, and presented as follows:

$\mathrm{TE}=\frac{f(X i ; \beta) \cdot \exp (\mathrm{Vi}-\mathrm{Ui})}{f(\mathrm{Xi} ; \beta) \cdot \exp (\mathrm{Vi})}=\exp (-\mathrm{Ui})$

Where $f(\mathrm{Xi} ; \beta) \cdot \exp (\mathrm{vi}-\mathrm{ui})$ is the observed output $(\mathrm{Y})$ and $f(\mathrm{Xi} ; \beta) \cdot \exp (\mathrm{vi})$ is the frontier output( $\left.\mathrm{Y}^{*}\right)$.

The error term (Vi) permits random variations in output due to factors outside the control of the farmer like weather and diseases as well as measurement error in the output variable, and is assumed to be identically, independently and normally distributed with mean zero and constant variance $\left(\delta_{\mathrm{v}}^{2}\right)$; i.e., $\mathrm{V}_{\mathrm{i}} \sim \mathrm{N}\left(0, \delta \mathrm{v}^{2}\right)$.

The $\mathrm{Ui}$ is an inefficiency component of error term and one sided none negative $(U>0)$ random variables, assumed to be independently distributed as truncation at $\mu$ of the normal distribution and

$\operatorname{variance}(\delta)$,ie.,Ui N $(\mu \mathrm{i})$.

Where $\mu \mathrm{i}$ is given by: $\mu \mathrm{i}=\mathrm{Zi} \delta$

Where:

$\mathrm{Zi}$ is a $(1 \mathrm{x} \mathrm{M})$ vector of exogenous explanatory variables associated with the technical inefficiency effects in the $\mathrm{i}^{\text {th }}$ time period and $\delta$ is an $(\mathrm{Mx} 1)$ vector of unknown parameter to be estimated.

The maximum likelihood estimation the stochastic frontier model yields the estimate for beta $(\beta)$, sigma squared $(\sigma 2)$ and gamma $(\gamma)$, and are variance parameters; $\gamma$ measures the total variation of observed output from its frontier output.

\section{Result and Discussion}

\subsection{Estimation of the production function}

Before discussion the estimation of, let us see the summary of variables which have significantly correlated with technical efficiency of wheat producing farmers at the study area. The average family size of the study area is 5.90 with standard deviation of 2.29 which showed significant correlation with technical efficiency of wheat production. The average age of household head in the survey area was 42.36 . It also ranges from 18 to 80 . The rural non-farm economy includes both non-farm wage employment and non-farm self-employment (though it excludes agricultural wage employment), and it lumps together a highly diverse collection of activities, including trading, agro-processing, manufacturing, construction, and commercial and service activities. Different opportunities in the non-farm economy are open to different groups. Household income was operationalized as a composite, summated measure of all major forms of income received plus the value of agricultural production generated by the household per months. Having more income generated in the form of non/off-farm income also influences the level of household's technical efficiency. The mean monthly non/off-farm income earned for the study area is 319.19 TB with standard deviation of 1069.54. It ranges from 0 to 10000ETB.

Table below reports the results provided by the Stochastic frointer approach model. The first part of the table presents the estimated parameters of the production function. Expected positive signs are found for all convential inputs used in production of whaeat. The second part of the analysis is determinats of technical efficiecy. The predicted score of each households were regressed on the household socio-economic and demographic fcators. 
Table 4: Maximum likelihood estimates of parameters of stochastic frontier Cobb-Douglas production function

\begin{tabular}{lcc}
\hline In put variables & Coefficient & Stdard error \\
\hline Log of seed used in kgs & $0.210^{* * *}$ & 0.055 \\
\hline Log of land used for wheat production in hectare & $0.135^{* * *}$ & 0.02 \\
\hline Log of the amount of labour used in hours & $0.071^{* * *}$ & 0.019 \\
\hline Log of fertilizer applied in kgs & $0.189 * * *$ & 0.041 \\
\hline Log of herbicide applied in liters & $0.532^{* * *}$ & 0.103 \\
\hline Constant term & 1.78 & 0.273 \\
\hline /nsig2v & $-4.95 * * *$ & 0.396 \\
\hline /lnsig2u & $-1.36 * * *$ & 0.12 \\
\hline sigma_v & 0.08 & 0.01 \\
\hline sigma_u & 0.51 & 0.03 \\
\hline sigma2 & 0.26 & 0.03 \\
\hline Lambda & 6.003 & 0.04 \\
\hline Number of obs $=$ & & \\
\hline
\end{tabular}

Note: $* * *$ represents level of significance at $1 \%$,

Source: Own computation result based on survey data (2019)

\subsubsection{Technical Efficiency Scores}

Given the functional form used, estimation procedure implemented, distributional assumption of the inefficient effect, Ui, the mean technical efficiency is estimated to be 67 percent. This value indicates that most farmers are not technically efficient in producing wheat in the study area in that on average they can increase the output they are getting by 33 percent without increasing the existing level of inputs; labor, area and seed.

Conversely, farmers on average could decrease inputs (labor, herbicide, area, fertilizer and seed) by 33 percent to get the output they are currently getting if they use inputs efficiently. In another words, since physical output considerations were important for wheat producers, they could increase production by an average 33 percent with a given inputs and currently available technology by operating at full technical efficiency level. Table 5: Estimated technical efficiencies of the sampled farmers

\begin{tabular}{llllll}
\hline Variable & Obs & Mean & Std. Dev. & Min & Max \\
\hline Tchnically efficiecy & 344 & 0.67 & 0.23 & 0.06 & 0.97 \\
Technical inefficiecy & 344 & 0.33 & 0.23 & 0.02 & 0.93 \\
\hline
\end{tabular}

Various regression diagnostics were performed to ensure unbiasedness and efficiency of the OLS regression estimates, and validity of the hypothesis tests. The models were tested for multicollinearity in the independent variables using variance inflation factors (VIFs). The averageVIF were 1.12 indicating an absence of multicollinearity. The Breusch Pagan Godfrey test was impleted to test hetroscedasticity and were corrected using robust standard errors.

Understanding the source of technical inefficiency and its extent is very important for policy making to address the problem of farmers. In this regard, demographic, socio-economic farm and farmer-specific and institutional variables were hypothesized to affect level of technical inefficiency of wheat growing farmers of the study area.

\subsubsection{Determinants of Technical efficiency}

The Sources of inefficiecy were westimated using OLS as follows: 
Table 6: OLS results of determinants of technical inefficiecy

\begin{tabular}{|c|c|c|}
\hline Independent variables & Coef. & Std. Err. \\
\hline Educational attainment of household head & $-0.008 * *$ & 0.004 \\
\hline Sex of household head & $-0.113 * * *$ & 0.030 \\
\hline Family size in numbers & $0.035 * * *$ & 0.005 \\
\hline Age of the household head & 0.0001 & 0.001 \\
\hline Livestock ownership in TLU & -0.001 & 0.002 \\
\hline Asset owned in ETB & $0.001 * * *$ & 0.000 \\
\hline Non/off- farm income in ETB & 0.00019 & 0.000 \\
\hline Receved credit & -0.035 & 0.022 \\
\hline Number of extension visit & $-0.002 * *$ & 0.001 \\
\hline Adoption of new variety seed & $-0.004 * * *$ & 0.001 \\
\hline distancetoallweatherroad & $-0.004 * * *$ & 0.001 \\
\hline Membership in iddir & $-0.127 * * *$ & 0.034 \\
\hline Membership in equb & $-0.088 * * *$ & 0.024 \\
\hline Cons & $0.447 * * *$ & 0.063 \\
\hline \\
\hline \multicolumn{3}{|l|}{$F(13,307)=14.8$} \\
\hline \multicolumn{3}{|l|}{ Prob $>F=0.0000$} \\
\hline$R$-squared $=0.374$ & & \\
\hline
\end{tabular}

Note: $* * *, * *, *$, represent level of significance at $1 \%, 5 \%$ and $10 \%$, respectively

Source: Own computation result based on survey data (2019)

Education attainment of the household This variable has a negative and a statistically significat at $5 \%$ on the level of wheat inefficiecy. Education and literacy have been identified as important factors in determining decisions to adopt productivity enhancing technologies among farmers.

The variable has a negative effect on the level technical efficiency of wheat production. Since there might be limited opportunities of raising the level of education of farmers in the short term, intensifying farmer training programmes through various innovative and vocational education programs and extension delivery systems would be more practical. In the medium-term, policies should be geared towards promoting formal education as a means of enhancing efficiency in agricultural produc

Sex household head: Male headed households are usually easily follow and have the opportunitit to follow the crop field. This variable is statisticall significant and negatively affects the levele of inefficiecy of wheat production. This result could arise because a larger fraction of women spend time doing other nonfarming household activities whose output is not measured here. It is also possible, however, that the low efficiency scores of female headed households are the result of poor access to new technologies, poor access to capital needed to invest in these technologies as well as poor access to agricultural extension services. male headed households had higher access to fertilizer, pesticide and extension services. They were more likely to use animal traction, and to be involved in cash cropping than the female headed household.

Asset owned: The value of assets owned also showed a positive effect on technical inefficiency as hypothesised and was significant at $1 \%$ level. The results indicated that most assets owned by households are not productive assets. This result contradicts the findings of Tchale (2009) also who found that smallholder crop farmers in Malawi, where he observed that assets owned by the farm household normally serve as security to guarantee access to loans by farmers, which ensures availability of funds to acquire farm inputs, hence increasing the farm's technical efficiency.

Extension contact: Extension services also showed a negative and significant influence on technical inefficiency at $5 \%$ level. According to the findings, whreat farmers who accessed extension services showed a higher level of technical efficiency than those who failed to access the services.Similar findings were reported by Illukpitiya (2005) among rural households in Sri-lanka. Illukpitiya argued that farmers who received extension service were more . Family size: The positive sign coefficiect of the family size variable indicates that wit increase in family size inefficiecy increases. This might be due to the fact large families usually contains more dependent households. This composition of households aggravates the level of household's technical inefficiecy.. This situation can occur due to various reasons. Firstly, if there is poor managerial ability to effectively utilize the available labor force in the family, large family becomes costly instead of facilitating production. Secondly, the constituents of the household members also matters. If there are more dependant members in the family (younger than 16 years and older than 65 years) the larger family size is higher burden for the productive household members. This increases economic/ cost inefficiency. This result corroborates the findings f ESSA(2011).

Distance to nearby all wheather road: Distance is also another variable affecting technical inefficiency of 
farmers. In many empirical studies it is hypothesized that distance between plot and home increases the level of inefficiency of farmers. In line with this hypothesis, the coefficient of the variable is found to negative and statistically significant at 1 percent level of significance. The more distant the farmer from road, the less technically inefficient the farmer is. This could be due to the fact that; one, the level of close supervision may not be so strong when the plots are far away from home. This result is consistent with the findings of Ogada et al. (2014). This relationship is straight forward. Farm households that lie closer to roads and markets are able to source inputs more easily and at lower transaction cost.

Adption new variety seed: The coefficient of the dummy representing use of new whaet variety seeds is statistically significant at the 1 percent level. The negartive sign of the coefficent of the variable indicates that plots with new variety seeds are more efficient than plots using local seeds.

\section{Conclusion and Recommendations}

This study set out to estimate levels of technical efficiency in wheat production among smallholder farmers in in Bale-Zone. Given the functional form used, estimation procedure implemented, distributional assumption of the inefficient effect, Ui, the mean technical efficiency is estimated to be 67 percent. This value indicates that most farmers are not technically efficient in producing wheat in the study area in that on average they can increase the output they are getting by 33 percent without increasing the existing level of inputs; labor, area and seed.

Since wheat is the one of the staple food in Ethiopia, high productivity and efficiency in production are therefore critical for food security in the country.

Government bodies especially Research and higher education institutions as well as none government institutions should jointly work to gather to increase the level of technical efficiency of wheat producing farmers.

\section{References}

Aigner, D.C.A, K, Lovell and P.Schmidt (1977). Formation and Estimation of stochastic production Function models; Journal of Econometric,

BF_EDD (Bale Zone Finance and Economics Development Department), (2005), Physical and Socio-economic profile of Bale zone; department of planning and Budget

CSA (Central Statistical Agency)(2018), The Federal Democratic Republic of Ethiopia, Central Statistical Agency, Agricultural sample survey, volume I: Report on Area and Production of Major Crops, Statistical Bulletin 532, Addis Ababa, Ethiopia.

Hassen Beshir, (2016), Technical Efficiency Measurement and Their Differential in Wheat Production: The Case of Smallholder Farmers in South Wollo Wollo University, Department of Agricultural Economics

Kaleb Kelemu and Workneh Negatu (2016). Analysis of levels and determinants of technical efficiency of wheat producing farmers in Ethiopia .Ethiopian Institute of Agricultural Research, Ethiopia. Addis Ababa University, Ethiopia.

Kothari, C. (2004). Research Methodology: Methods and Techniques, $2^{\text {nd }}$ Edition, Wisha, Prakasha, New Delhi.

Maurice Juma Ogada, Dianah Muchai, Germano Mwabu, Mary Mathenge. 2014. Technical efficiency of Kenya's smallholder food crop farmers: do environmental factors matter?

Solomon Teshome Wassie ( 2014). Efficiency of Agricultural Production Technical Efficiency of Major crops In Ethiopia: Stochastic Frontier Model

World Bank (2016). World Bank Country Data "GDP growth (annual \%)", htt: //data world bank.org/indicator/Ny.GDP.MKTP.KD.ZG.? /location=Ethiopia. 